\title{
Clinical Molecular Testing: Subspecialty, Entry-Level or Specialist Certification?
}

\author{
ALAN LENNON, PETER HU
}

\begin{abstract}
Some clinical laboratories require workers who have basic knowledge in molecular techniques (such as fluorescent in situ hybridization and polymerase chain reaction). Exclusively molecular diagnostic laboratories need workers to be competent in a variety of cutting edge molecular technologies, such as DNA sequencing, array-based comparative genomic hybridization, quantitative polymerase chain reaction, and many other techniques. Having only one certification for molecular biology at the entry level, as newly prescribed by the Board of Certification, doesn't accurately define the two very differently trained types of people these differing types of laboratories require. Creating a second molecular certification, at the specialist level, would address this issue positively.
\end{abstract}

INDEX TERMS Molecular Biology, Certification, Board of Certification, Entry-level, Specialist

ABBREVIATIONS: FISH-fluorescence in situ hybridization; PCR-polymerase chain reaction; aCGHarray-based comparative genomic hybridization; NCANational Credentialling Agency; BOR-Board of Registry; BOC-Board of Certification

Clin Lab Sci 2011;24(4):208

Alan Lennon, PhD, FACMG, Clinical Cytogenetics, Pathgroup, Inc., Nashville, TN

Peter $H u, P h D, \quad M B(A S C P)^{C M}, \quad C G(A S C P)^{C M}$, Molecular Genetic Technology Program, School of Health Professions, University of Texas-M.D. Anderson Cancer Center, Houston, TX

Address for Correspondence: Alan Lennon, PhD, FACMG, Director, Clinical Cytogenetics, Pathgroup, Inc., 658 Grassmere Park, Suite 101, Nashville, TN 37211, 615-562-9477,palennon@pathgroup.com

\section{INTRODUCTION}

Here an attempt is made to illuminate the differences in ancillary molecular testing performed in more traditional medical laboratories and the variety of complex molecular testing performed in exclusively molecular diagnostic laboratories. Understanding these differences leads to the belief that personnel trained to perform molecular testing in these different settings need different precertification training and perhaps different certification levels, for example, entry-level versus specialist.

There are many types of laboratories that perform molecular testing. In some more traditional hospitalbased laboratories, for example, there is a need for cytotechnologists to perform tests like fluorescence in situ hybridization (FISH) that determine Her2/neu gene copy number amplification on formalin-fixed paraffin-embedded breast biopsies. These results determine whether or not patients correctly receive the beneficial Herceptin ${ }^{\odot}$ (trastuzumab) therapy, at an annual cost of therapy at about $\$ 100,000$ per patient. Cytotechnologists might also need to determine chromosomal copy number (aneuploidy) in cytospin samples from urine for early detection of bladder cancer recurrence. And, there are many automated point-ofcare testing platforms which allow clinical laboratory scientists to perform basic polymerase chain reaction (PCR)-based tests on nucleic acid samples extracted from a variety of tissues.

The molecular tests that clinical laboratory scientists and cytotechnologists need to be able to perform in the modern laboratory are very important, but predominantly fall within the categories of relatively simple molecular tests: FISH, PCR and GenProbe type assays. Molecular diagnostic testing, however, has developed quite far beyond the simplicity of those two testing methodologies. 


\section{CLINICAL PRACTICE}

Laboratories which perform molecular testing exclusively typically perform tests in one or more of the following four areas: constitutional genetics, cancer genetics, infectious diseases, and human identity. There are complex testing platforms such as array-based comparative genomic hybridization $(\mathrm{aCGH})$ which can scan entire genomes quickly and effectively for chromosomal microduplications and microdeletions. Fluorescent labeling techniques and machines that perform capillary-based electrophoresis are largely replacing agarose and acrylamide slab gel-based electrophoresis for providing DNA fragment sizing which is so important in human identity testing and other PCR product sizing, as in determining chromosomal translocation breakpoints. With newer modifications, similar machines can sequence the whole genomes of multiple people in only a few short weeks, leading the way to truly personalized medicine. These modifications allow medication dosages to be determined based upon the metabolic factors determined by DNA sequence at multiple gene locations. (Sequencing of the entire genome of just one individual in the Human Genome project took almost 5 years!)

Real-time polymerase chain reaction technology not only allows the elimination of slab gels and electrophoresis for product analysis in allelic determination assays, but has allowed the quantitation of initial copies of input DNA and RNA (once RNA is converted to cDNA using reverse transcription) for viral load determination. Southern blotting techniques involve separating DNA fragments on large gels, transferring the separated fragments to a membrane, and affixing them there. Fragments of interest are localized on the membrane using radioactive or chemiluminescent probes, and detected via autoradiography. The Southern blotting technique is invaluable for detecting large fragments, in diseases such as fragile $\mathrm{X}$ and myotonic dystrophy, in which the disease-causing trinucleotide repeat expansions are too large to be successfully generated by polymerase chain reaction.

In addition, molecular diagnostic laboratories around the United States use a variety of other techniques in automated, high-throughput, cost-effective platforms that require a great deal of knowledge to set up and analyzed correctly. Some of these include branched
DNA, hybrid capture, transcription-mediated amplification, cleavase-based assays, home-brew fluorescence in situ hybridization assays (where the DNA of interest is ordered using public genomic databases and fluorescently labeled in house), Invader assay, strand displacement assays and pyrosequencing.

It should be quite evident that the knowledge and competency needed by entry-level medical technologists or cytotechnologists to perform simpler molecular testing is quite different from that required by an entrylevel person entering an exclusively molecular diagnostics laboratory. There is quite a difference in both experience (competency) requirements and scope of practice of someone with entry level clinical chemistry and entry level hematology certification compared to specialists in those same areas as seen in Table 1. Similarly, there is quite a difference in scope of practice of molecular techniques of clinical laboratory scientists and cytotechnologists who might be certified at the entry level in molecular biology and those molecular biologists who graduate from approved molecular programs and enter a molecular diagnostic laboratory, also with the same entry-level certification. The proposed scope of practice of the molecular biologist entering at the entry level into a molecular diagnostic laboratory (Table 1) is as different and thus as specialized as are the entry-level and specialist scope of practice of both the clinical chemistry and hematology certification areas. This proposed scope of practice for the molecular biologist in Table 1 entering at the entry-level in the molecular diagnostic laboratory is quite reasonable based upon the 2010 Entry-Level Molecular Genetic Technologist Competency Survey by Juroske et al. (2010) which surveyed molecular diagnostic laboratories all across America.

Recently, with the merger of National Credentialing Agency (NCA) and ASCP Board of Registry (BOR) into the Board of Certification (BOC), the molecular certifications from these were merged into one, at the entry level, eliminating the specialty certification offered by NCA for those graduating from an approved molecular diagnostics program or gaining eligibility via one year of on-the-job training. Route one of the new BOC exam in molecular biology also eliminated a more stringent competency requirement (gained by experience in a molecular laboratory or graduating from a molecular program) to sit for the molecular exam as 


\section{CLINICAL PRACTICE}

Table 1. Correlation Between Scope of Practice With BOC Exam

\begin{tabular}{ll}
\hline $\begin{array}{l}\text { CORRELATING SCOPE OF PRACTICE } \\
\text { WITH CATEGORICAL - } \\
\text { CHEMISTRY EXAM }\end{array}$ & $\begin{array}{l}\text { CORRELATING SCOPE OF PRACTICE } \\
\text { WITH CATEGORICAL - } \\
\text { HEMATOLOGY EXAM }\end{array}$ \\
\hline $\begin{array}{l}\text { Clinical experience in } 5 \text { of the } 8 \\
\text { procedures listed below }\end{array}$ & $\begin{array}{l}\text { Clinical experience in the following } \\
\text { Blood smear, evaluation and differential } \\
\text { Carbohydrates }\end{array}$ \\
$\begin{array}{l}\text { Clectrolytes } \\
\text { Enzymes }\end{array}$ & $\begin{array}{l}\text { Routine coagulation tests (e.g., PT, APTT) } \\
\text { Quality Control: performance and evaluation }\end{array}$ \\
Heme Compounds & Clinical experience in 2 of the 3 \\
Lipids/liproproteins & procedures listed below \\
Non-protein nitrogen compounds & Instrument maintenance \\
Proteins & Miscellaneous tests (e.g., reticulocyte, ESR, \\
Point-of-care & sickle screen manual cell count) \\
Clinical experience in 3 of the 5 & Other coagulation tests (e.g., fibrinogen, \\
procedures below & factor assays) \\
Bood gases &
\end{tabular}

Blood gases

Quality control program

Therapeutic drug monitoring

Toxicology

Vitamins/hormones

\section{CORRELATING SCOPE OF PRACTICE WITH SPECIALIST - CHEMISTRY EXAM}

Clinical experience in 8 of the 12 procedures listed below

Carbohydrates

Electrolytes

Enzymes

Heme compounds

Lipids/lipoproteins

Non-protein nitrogen compounds

Proteins

Point-of-care

Blood gases

Hormones/vitamins

Therapeutic drug monitoring

Toxicology

Clinical exp. in 2 of the 6 procedures

below

New test development

Procurement of laboratory equipment

Quality control program

Regulatory compliance

Supervisory experience

Teaching

QA/QI

Hemoglobinopathy evaluation

\section{CORRELATING SCOPE OF PRACTICE WITH MOLECULAR BIOLOGY EXAM}

\author{
Cytogeneticist \\ DNA/RNA extraction \\ Fluorescence In Situ Hybridization (FISH) \\ Microscopy (signal analysis) \\ Array-CGH \\ Medical Laboratory Scientist \\ DNA/RNA extraction \\ Nucleic Acid Testing (e.g., Gen- \\ Probe assay, PCR, RT-PCR, \\ Branched DNA, Ligase Chain \\ Reaction, TMA) \\ Cytotechnologist \\ DNA/RNA extraction \\ Fluorescence In Situ Hybridization (FISH) \\ Microscopy (signal analysis) \\ Signal amplified hybridizaton \\ (hybrid capture for HPV detection) \\ Histotechnologist \\ DNA/RNA extraction \\ Chromogenic in situ hybridization(CISH) \\ Fluorescence In Situ Hybridization (FISH) \\ PROPOSED SPECIALTY MOLECULAR \\ BIOLOGY EXAM CORRELATING \\ WITH SCOPE OF PRACTICE IN A \\ FULL SERVICE MOLECULAR \\ DIAGNOSTIC LABORATORY
}

CORRELATING SCOPE OF PRACTICE
WITH SPECIALIST - HEMATOLOGY
EXAM

Clinical experience in the procedures listed below

Blood smear, evaluation and differential

Complete blood count

Instrument maintenance

Miscellaneous tests (e.g., reticulocyte,

ESR, sickle screen)

Quality control performance, and evaluation

Routine coagulation tests (e.g., PT, APTT)

Other coag. tests (e.g., fibrinogen)

Clinical experience in 5 of the 12 procedures

listed below

Advanced coagulation (e.g., inhibitor assays)

Body fluid evaluation

Bone marrow prep or evaluation

Budgeting/inventory control/purchasing

Cytochemical stains

Flow cytometry

Method evaluation

Personnel management

Platelet function studies

PT/PTT mixing studies
Clinical experience in 7 of the 11

procedures listed below

DNA/RNA extraction

Signal amplified hybridization assays

(e.g., Gen-Probe assay, hybrid capture assays)

Non-amplified hybridization assays

(e.g., Southerns, dot blot hybridizations, in situ hybridizations)

Target amplification assays (e.g., PCR, RT-PCR, in situ PCR)

Fluorescence In Situ Hybridization (FISH) Chromogenic in situ hybridization (CISH)

Microscopy (signal analysis)

Array-CGH and analysis

Oligo-arrays and analysis

Genotyping assays (e.g., capillary

electrophoresis, pyrosequencing)

Next generation sequencing well, as required previously by all NCA's eligibility routes. Now, those certified in other clinical laboratory disciplines (medical technology, cytotechnology) or even subspecialties (microbiology and blood banking, etc) can sit for the molecular exam with only minimal training in molecular biology within their existing 


\section{CLINICAL PRACTICE}

clinical internship. This is quite different from the training of those who enter a molecular diagnostic training program or those who get one year of on-thejob training in a molecular laboratory prior to becoming eligible to sit for the molecular exam. While the BOC eligibility routes for the certification in molecular biology are the same as they were for BOR, you can see the dilemma that molecular laboratories will continue to face in the future: Does certification in molecular biology by BOC indicate that a prospective employee is truly competent to effectively function in an exclusively molecular diagnostic laboratory?

Perhaps the simplest solution is to create two molecular biology certification exams: entry-level and specialist. The current BOC molecular biology eligibility routes allow medical technologists, cytotechnologists and others to prepare for and become certified at the entry level in molecular biology and feel more competent in performing the important molecular tests they are increasingly required to perform. If BOC also established a molecular biology specialist exam, molecular diagnostics laboratories could feel that employees they hired which were certified in molecular biology at the specialist level were able to effectively use the many types of more complicated molecular testing platforms that are required to provide the answers needed by their patients and requesting physicians. With the lack of real experience (indicating competence) that clinical laboratory scientists or cytotechnologists, for instance, might have to demonstrate to become eligible to sit for the entry-level molecular biology certification exam, quite possibly one year of on-the-job training within a molecular diagnostics laboratory or graduating from a molecular diagnostics training program might suffice for eligibility to sit for the specialist examination in molecular biology. Alternatively, providing the clinical laboratory scientists, cytotechnologists, blood bankers, etc., with subspecialty certifications and on-the-job trainees and molecular diagnostics program graduates with the entry level certification might suffice. This is conversation that needs to take place within our educational/training/certification/laboratory community soon.

\section{REFERENCE}

1. Juroske, D., Simien, C., Lennon, A., Hu, P. (2010). 2010 Entry-Level Molecular Genetic Technologist Competency Survey. J Assoc of Genet Technol, 36(3):116-9.

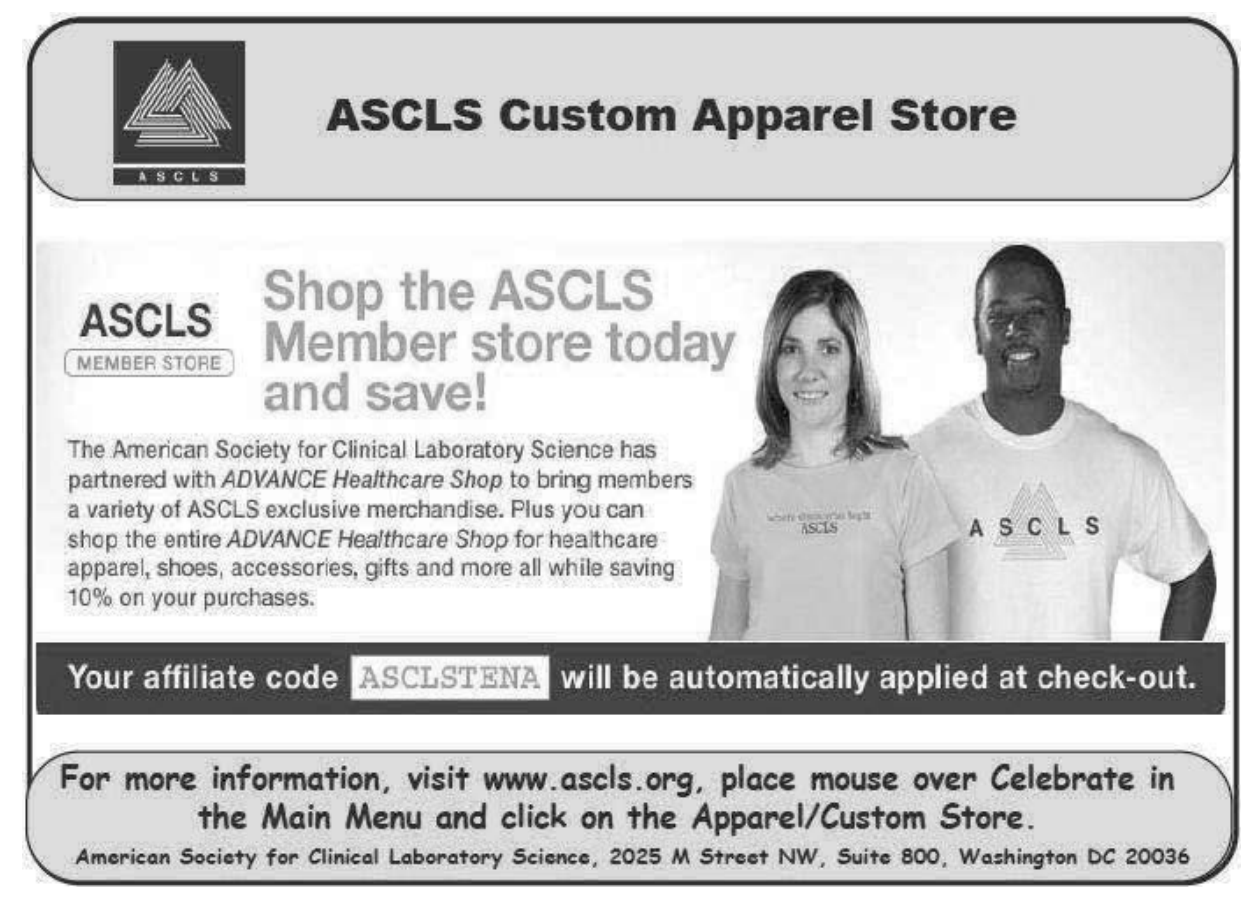

